\title{
A Relação entre as Representações acerca das Figuras Parentais e as Competências Sociais em Crianças Maltratadas e não Maltratadas
}

\author{
Mariana Lopes de Sousa ${ }^{1}$ \\ Orlanda Cruz \\ Universidade do Porto
}

\begin{abstract}
RESUMO - Assumindo a centralidade das representações acerca das figuras parentais na trajetória desenvolvimental, este estudo teve como objetivo analisar a relação destas representações com as competências sociais de crianças maltratadas e não maltratadas. Participaram, nesta investigação, 62 crianças em idade escolar (22 maltratadas e 40 não maltratadas). As representações acerca das figuras parentais foram avaliadas com a Entrevista de Avaliação das Representações acerca das Figuras Parentais e as competências sociais com a adaptação portuguesa da Social Skills Rating System - Form for Teachers. Nas crianças maltratadas, não se verifica a associação entre as representações das figuras parentais e as competências sociais, observada em amostras normativas. Os resultados sugerem que os dois grupos atribuem significados distintos aos comportamentos parentais.
\end{abstract}

Palavras-chave: representação mental em crianças, representação parental, relações pais-criança, competência, abuso da criança

\section{Relationship between Mental Representations of Parents and Social Competence of Abused and Nonabused Children}

\begin{abstract}
Considering the importance of mental representations of parental figures in the developmental trajectory of children, this study aimed to analyze the relationship of these representations with the social competence of abused and nonabused children. A total of 62 school-aged children participated in this study ( 22 maltreated and 40 nonmaltreated). The mental representations of the children were assessed with the Children Representations about Parental Figures Interview, while social competence was assessed with means of the Portuguese version of the Social Skills Rating System - form for teachers. The association between representations of parental figures and social competence observed in normative samples does not exist in abused children. These results suggest that abused and nonabused children attribute different meanings to their parents' behavior.
\end{abstract}

Keywords: mental representation in children, parental representation, parent child relations, competence, child abuse

A experiência de maus-tratos constitui fator de risco para a trajetória desenvolvimental, podendo exercer grandes repercussões negativas extensíveis ao desenvolvimento físico, emocional, social e cognitivo da criança (Barnett, 1997). A vivência de situações de maus-tratos encontra-se estreitamente associada às competências sociais da criança (Shields, Ryan, \& Cicchetti, 2001). Em comparação com as não maltratadas, as crianças maltratadas tendem a apresentar um locus mais externo de controle (Bolger \& Patterson, 2001), a ser menos empáticas e sensíveis nas interações pessoais (Straker \& Jacobson, 1981) e a incorrer, com maior frequência, em comportamentos agressivos (Johnson et al., 2002) e de ruptura com a regra (Torres, Maia, Veríssimo, Fernandes, \& Silva, 2012).

Além das dificuldades na interação social, as crianças que vivenciaram experiências de maus-tratos tendem a apresentar dificuldades de regulação emocional e comportamental (Maughan \& Cichetti, 2002), que potencializam a emergência de problemas de internalização (Bolger \& Patterson, 2001) e de externalização (Toth, Cicchetti, Macfie, Rogosch, \&

1 Endereço para correspondência: Rua Alfredo Allen, Porto, Portugal. CEP: 4200-135. E-mail: marianalopesdesousa@gmail.com
Maughan, 2000). As crianças maltratadas têm maior risco de desenvolver sintomatologia depressiva (e.g. Toth, Manly, \& Cicchetti, 1992) e ansiosa, bem como de apresentar queixas somáticas (Culp, Howell, Culp, \& Blankemeyer, 2001). Apresentam, também, mais reações de irritabilidade explosiva, desobediência e dificuldades no relacionamento interpessoal (Milot, Éthiet, St-Laurent, \& Provost, 2010).

O estudo da parentalidade maltratante surge, assim, como um imperativo na análise dos processos psicológicos associados ao impacto da experiência de maus-tratos nas competências sociais das crianças. $\mathrm{O}$ estudo das representações mentais das crianças acerca das figuras parentais permite cumprir esse desígnio.

As representações acerca das figuras parentais são internalizadas pela criança no contexto das relações afetivas precoces, modelando a forma e a qualidade das relações por ela estabelecidas, ao longo da sua trajetória desenvolvimental (Clyman, 2003; Shields et al., 2001). Essas representações são estruturas mentais de natureza cognitiva e afetiva, que incorporam e integram as representações do self, do outro e da interação de ambos (Waldinger, Toth, \& Gerber, 2001). Funcionam como parâmetro para as experiências relacionais da criança (Solomonica-Levi, Yirmiya, Erel, Samet, \& Oppenheim, 2001). 
As representações mentais das crianças têm sido estudadas com base em metodologias narrativas, nomeadamente através de entrevistas semiestruturadas em que são apresentados inícios de histórias que a criança deve completar, através da construção de uma narrativa e da sua dramatização (e.g., Bretherton \& Oppenheim, 2003; Custódio \& Cruz, 2008). Os resultados da investigação baseada na análise comparativa do conteúdo das narrativas de crianças maltratadas e não maltratadas não suportam, de forma consistente, a existência de diferenças nas representações acerca das figuras parentais (cf. Clyman, 2003).

Algumas investigações revelam que, em comparação com os pares não maltratados, as crianças maltratadas tendem a representar as figuras parentais como menos responsivas (Warren, 2003), mais punitivas, agressivas e conflituosas (Toth et al., 2000). Nas suas narrativas, as crianças maltratadas tendem a mostrar menos empatia e preocupação perante o mal-estar físico e/ou emocional dos pares (KlimesDougan \& Kistner, 1990) e a envolver-se em menos comportamentos pró-sociais (Koenig, Cichetti, \& Rogosch, 2004). Assumem menos a perspetiva do outro e representam os adultos e os pares como menos responsivos face ao mal-estar emocional e aos comportamentos pró-sociais das personagens (Macfie et al., 1999). Tendem, igualmente, a descrever mais comportamentos de agressão física com os cuidadores e os pares (Buchsbaum, Toth, Clyman, Cicchetti, \& Emde, 1992), bem como mais comportamentos de ruptura com a regra (Koenig et al., 2004).

Todavia, outras investigações mostram que os conteúdos emergentes nas narrativas das crianças maltratadas não estão linearmente associados à sua experiência na interação com as figuras parentais (Macfie et al., 1999). A inconsistência dessa associação aponta para a possibilidade de, na construção das narrativas das crianças maltratadas, poderem interferir outros aspetos, além das representações das experiências vividas em contexto familiar.

No âmbito dessa discussão, surgem duas hipóteses explicativas: a representacional e a da regulação emocional (Clyman, 2003). A hipótese representacional preconiza que as crianças maltratadas tendem a descrever situações de conflito e tensão emocional, reproduzindo, nas suas narrativas, as experiências vivenciadas no contexto familiar (Herzberger, Potts, \& Dillon, 1981). Por sua vez, a hipótese da regulação emocional baseia-se no pressuposto de que as crianças modificam, ou evitam retratar, as interações familiares negativas, para evitar o confronto com as emoções por elas despertadas, sendo as suas narrativas permeadas por mecanismos de regulação emocional (Toth, Cicchetti, Macfie, \& Emde,1997). Desse modo, as narrativas construídas pelas crianças sobre as figuras parentais parecem ser influenciadas não só pelas representações das interações familiares como também pelos mecanismos de regulação das emoções a elas associadas (Clyman, 2003).

A investigação mostra que as representações acerca das figuras parentais estão associadas ao comportamento social da criança (Laible, Carlo, Torquati, \& Ontai, 2004). As crianças que representam o comportamento materno como ambivalente, isto é, pautado pela disciplina inconsistente e pelo afeto negativo, tendem a apresentar mais problemas de comportamento (Solomonica-Levi et al., 2001). As crianças que representam as figuras parentais como recorrendo, mais frequentemente, à punição física tendem a ser menos competentes social e academicamente (Shields et al., 2001) e a apresentar mais problemas de internalização (Oppenheim, Emde, \& Warren, 1997). Além disso, os comportamentos parentais punitivos predizem a descrição de interações agressivas dos protagonistas das narrativas e os comportamentos externalizados da criança. Em consonância com esses resultados, a literatura mostra que baixos níveis de responsividade emocional e altos níveis de rejeição estão associados a problemas de internalização e externalização, sendo que os comportamentos parentais de afeto predizem negativamente os sintomas de externalização (e.g., Muris, Meesters, \& van den Berg, 2003). Os comportamentos parentais de apoio estão negativamente associados a comportamentos delinquentes e agressivos (Oppenheim et al., 1997) e positivamente associados a comportamentos pró-sociais e de aceitação pelos pares (Shields et al., 2001).

Esses resultados são corroborados pela investigação centrada na perspetiva dos pais, mostrando que, quando os pais afirmam recorrer à punição física e à agressão verbal, os filhos expressam menos bem-estar (Amato \& Fowler, 2002), evidenciam menor autocontrole (Cruz, 1999), assim como mais problemas de internalização e de externalização (Gershoff, 2002).

Assumindo as representações acerca das figuras parentais como decisivas na trajetória desenvolvimental, este estudo teve como objetivo analisar a relação dessas representações com as competências sociais em crianças maltratadas, dado que a especificidade dessa relação é documentada de forma insuficiente na literatura. A investigação mostra que a influência das práticas educativas parentais na criança pode variar em função do meio social em que a família está inserida, nomeadamente da normatividade dessas práticas (Baumrind, 2012). Por exemplo, se os comportamentos de controle punitivo forem habituais em uma determinada comunidade, podem não ter um impacto negativo, sendo possível que a criança não lhes atribua um significado negativo e os interprete como manifestações de atenção e afeto. Desse modo, é possível que a representação de comportamentos parentais similares possa estar associada a diferentes competências nas crianças maltratadas e não maltratadas.

Tendo essas premissas como eixo norteador, este estudo tem como objetivos:

1. Analisar comparativamente as representações acerca das figuras parentais em função da experiência de maus-tratos. Na investigação desenvolvida nesse domínio, surgem duas hipóteses - a representacional e a da regulação emocional -, pretendendo-se testálas neste estudo.

2. Analisar comparativamente as competências sociais das crianças em função da experiência de maustratos. A literatura suporta a existência de fragilidades nessas competências, nas crianças maltratadas.

3. Analisar a relação das representações sobre as figuras parentais com as competências sociais das crianças em função da experiência de maus-tratos. Dada a insuficiência de dados empíricos na documentação 
dessas diferenças, essa questão será objeto de uma análise exploratória.

\section{Método}

\section{Participantes}

Participaram, neste estudo, 62 crianças, sendo 22 maltratadas e 40 não maltratadas. $O$ grupo de crianças maltratadas foi constituído por 15 meninas e 7 meninos, entre os 6 e os 12 anos de idade $(M=8.05 ; D P=1.84)$, a frequentar o $1^{\circ}$ ou $2^{\circ}$ ciclo do ensino básico ${ }^{1}$. Estas crianças foram retiradas à família biológica, por serem vítimas de mau-trato, tendo sido institucionalizados em Centros de Acolhimento Temporários (CAT). Quatro crianças provinham de um nível socioeconómico (NSE) médio e 18 de um NSE baixo . Quanto à natureza dos maus-tratos, 7 crianças tinham sofrido maus-tratos físicos; 6 , maus-tratos emocionais; e 20, negligência, havendo, como seria de esperar, uma sobreposição entre os diferentes tipos de maus-tratos. Relativamente ao tempo de residência no CAT, 17 crianças encontravam-se institucionalizadas há um ano ou menos e cinco há mais de um ano. $\mathrm{O}$ grupo de crianças não maltratadas foi integrado por 20 meninas e 20 meninos, entre os 8 e os 9 anos de idade $(M=8,43, D P=0,50)$, que viviam com a família biológica, provindo 20 de um NSE médio e 20 de um NSE baixo. Essas crianças frequentavam o $1^{\circ}$ ciclo de escolaridade e viviam com ambos os pais.

\section{Instrumentos}

Entrevista de Avaliação das Representações das Crianças acerca das Figuras Parentais (EARCFP). A EARCFP (Custódio \& Cruz, 2008) é uma entrevista semiestruturada, constituída por dez inícios de histórias que descrevem situações de interação de pais/mães e filhos, representativas da rotina das crianças em idade escolar. Foi construída com base na MacArthur Story Stem Battery (MSSB; Bretherton \& Oppenheim, 2003). Em cinco histórias, o tema dominante é o disciplinar, enquanto, nas restantes, predomina um tema de afeto. Nas histórias em que domina o tema disciplinar, a criança protagonista apresenta um comportamento socialmente desadequado. Nas histórias em que predomina o tema de afeto, a criança protagonista é descrita como estando numa situação de vulnerabilidade física e/ou emocional. A entrevista tem duas versões, diferenciadas em função da figura parental protagonista.

O procedimento de administração consiste em apresentar o início da história, sendo o processo de construção da narrativa estruturado com base em um conjunto de questões que visam explorar o seu conteúdo, tonalidade emocional dominante e estrutura: (a) Como é que achas que o(a) menino(a) se sente? Por quê?; (b) E a mãe/pai, como é que

$1 \mathrm{O} 1^{\circ}$ ciclo do ensino básico corresponde aos quatro primeiros anos de escolaridade, enquanto o $2^{\circ}$ ciclo do ensino básico se refere aos dois anos de escolaridade subsequentes. achas que ela/e se sente? Por quê?; (c) O que é que achas que a mãe/pai vai fazer?; (d) Por que é que achas que agiu dessa forma?; (e) E agora, como é que o(a) menino(a) se sente?; (f) E agora, como é que achas que a mãe/pai se sente?; ( $g$ ) Como termina a história?. Com vista a facilitar o processo de construção da narrativa, são utilizadas oito figuras ilustrativas das personagens que protagonizam as histórias (o menino, a menina, a mãe, o pai, o irmão, a irmã, o amigo e a amiga dos pais), cujo intuito é permitir à criança dramatizar a ação narrada.

O conteúdo das narrativas das crianças foi analisado com recurso a um sistema de codificação baseado no sistema de Custódio e Cruz (2008), que abrange: comportamentos parentais de afeto, comportamentos parentais disciplinares e clima emocional dominante na interação com as figuras parentais. Os comportamentos parentais de afeto incluem os comportamentos de aceitação (apoio, proteção, prestação de cuidados ou satisfação de desejos da criança) e de rejeição (desaprovação, insensibilidade face às necessidades e desejos, afastamento). Por sua vez, os comportamentos parentais disciplinares abrangem a punição (física e não física), a indução (explicações, justificações, apresentação de uma regra ou princípio a cumprir) e a ausência de confronto (ignorar a situação de conflito ou ceder às solicitações da criança para evitar o confronto com o comportamento desadequado).

Os comportamentos parentais de afeto e disciplinares foram avaliados em uma escala de três pontos (1-comportamento ausente; 2-comportamento com intensidade média; 3-comportamento muito intenso). O clima emocional foi aferido numa escala de 4 pontos (1-totalmente negativo; 4-totalmente ou quase positivo).

Para calcular o acordo intercodificador, as narrativas de $25 \%$ dos participantes foram cotadas por quatro investigadoras. Duas investigadoras cotaram as narrativas de dez crianças não maltratadas, em um total de 200 narrativas. As outras duas investigadoras cotaram as narrativas de seis crianças maltratadas, em um total de 120 narrativas. Foi calculado o coeficiente de acordo $\left[\mathrm{n}^{\circ}\right.$ de acordos/ $\left(\mathrm{n}^{\mathrm{o}}\right.$ de acordos $+\mathrm{n}^{\mathrm{o}}$ de desacordos)] e o Kappa ponderado. O coeficiente de acordo oscilou entre $92 \%$ e $100 \%$, sendo a média $97 \%$. Os valores do Kappa ponderado variaram entre 0,84 e 1 , sendo a média 0,89 .

Escalas de Avaliação da Competência Social (EACS). As competências sociais foram avaliadas através das Escalas de Avaliação da Competência Social - forma para professores (Lemos \& Meneses, 2002), que consiste na versão traduzida e adaptada do Social Skills Rating System (SSRS; Gresham \& Elliot, 1990). No estudo de adaptação à população portuguesa, foi encontrada uma estrutura multifatorial semelhante à proposta pelos autores do SSRS (Lemos \& Meneses, 2002).

Esse instrumento é composto por 54 itens, organizados em três escalas: (a) Habilidades Sociais, com 30 itens organizados em três subescalas (Autocontrole, Cooperação e Asserção); (b) Problemas de Comportamento, com 18 itens organizados em três subescalas (Problemas Externalizados, Problemas Internalizados e Hiperatividade); (c) Competência Académica, com 6 itens. Os resultados da última escala não foram utilizados neste estudo. A consistência interna das notas 
é elevada, à semelhança do que acontece em outros estudos (cf. Custódio \& Cruz, 2008; Lemos \& Meneses, 2002). Os coeficientes alpha de Cronbach para o Autocontrole, a Cooperação, a Asserção e Habilidades Sociais são 0,85; 0,$91 ; 0,85$ e 0,94 , respectivamente. Por seu turno, nas escalas de Problemas Externalizados, Problemas Internalizados, Hiperatividade e Problemas de Comportamento, os valores obtidos são 0,$93 ; 0,79 ; 0,87$ e 0,94 , respectivamente.

\section{Procedimento}

A coleta de dados foi realizada em três Centros de Acolhimento Temporário (CAT), no caso do grupo de crianças maltratadas, e em escolas, no grupo de crianças não maltratadas. Nos CAT, a realização das entrevistas foi autorizada pela direção técnica e, nas escolas, pela direção dos agrupamentos e pelos encarregados de educação.

Todas as crianças responderam às duas versões da entrevista, em um total de 20 narrativas. Metade das crianças respondeu, primeiro, à versão referente à figura materna e, depois, à versão relativa à figura paterna, tendo a ordem de aplicação das duas versões sido invertida com a outra metade dos participantes. A duração média da entrevista rondou os 50 minutos, embora variando em função do estilo de funcionamento de cada criança. As narrativas das crianças foram gravadas em áudio e transcritas para análise e codificação. De posse dos dados recolhidos junto à criança, os técnicos dos CAT e os professores titulares de turma preencheram a EACS, no grupo de crianças maltratadas e não maltratadas, respectivamente.

\section{Resultados}

\section{Análises Preliminares}

As narrativas produzidas pelas crianças face à figura paterna e à figura materna foram submetidas a análises comparativas e correlacionais. Os resultados revelam, por um lado, a ausência de diferenças estatisticamente significativas na forma como as crianças representam a figura materna e paterna e, por outro, a presença de correlações estatisticamente significativas de valor moderado e elevado entre as representações construídas pelas crianças sobre a figura paterna e a figura materna. Conforme os resultados, observa-se que as crianças representam as figuras parentais de forma semelhante, portanto foram utilizadas as médias das representações maternas e paternas para as seis variáveis (Aceitação, Rejeição, Punição, Indução, Ausência de Confronto e Clima Emocional), nas análises posteriores.

As representações das crianças e as competências sociais não diferem estatisticamente em função do sexo das crianças, nem estão estatisticamente associadas à sua idade. As representações das crianças não diferem também em função do NSE. As crianças de NSE médio apresentam mais habilidades sociais, nomeadamente de autocontrole $(M=1,25, D P=0,45)$ e cooperação $(M=3,57, D P=1,22)$, do que as de NSE baixo $(M=0,99, D P=0,46$ e $M=2.64$,
$D P=1,36$, respectivamente) $t(60)=-2,72, p<0,001$ e $t$ $60)=-2,22, p<0,05$, respectivamente. As crianças de NSE médio tendem, além disso, a apresentar menos problemas internalizados $(M=0,21, D P=0,33)$ e de hiperatividade $(M$ $=0,43, D P=0,51)$ do que as de NSE baixo $(M=0,40, D P=$ 0,42 e $M=0,69, D P=0,50$, respectivamente), $t(60)=1,93$, $p<0,06$ e $t(60)=1,94, p<0,06$, respectivamente.

\section{Diferenças entre Grupos nas Representações acerca das Figuras Parentais e nas Competências Sociais}

$\mathrm{Na}$ análise comparativa das representações acerca das figuras parentais, não foram encontradas diferenças estatisticamente significativas entre o grupo de crianças maltratadas e não maltratadas (ver Tabela 1).

No que tange às competências sociais, os resultados mostram que, com exceção da asserção, as crianças

Tabela 1. Médias, desvios-padrão e notas t das representações sobre as figuras parentais e das competências sociais em função da variável Grupo

\begin{tabular}{|c|c|c|c|c|c|}
\hline \multirow[t]{2}{*}{ Dimensões / Categorias } & \multicolumn{2}{|c|}{ Maltratadas } & \multicolumn{2}{|c|}{$\begin{array}{c}\text { Não } \\
\text { Maltratadas }\end{array}$} & \multirow[t]{2}{*}{$t$} \\
\hline & $M$ & $D P$ & $M$ & $D P$ & \\
\hline \multicolumn{6}{|l|}{$\begin{array}{l}\text { Representações F. } \\
\text { Parentais }\end{array}$} \\
\hline Aceitação & 37,91 & 5,49 & 39,92 & 5,85 & 1,33 \\
\hline Rejeição & 39,41 & 6,25 & 40,08 & 5,85 &, 42 \\
\hline Punição & 31,59 & 6,12 & 29,55 & 6,41 & $-1,22$ \\
\hline Indução & 22,45 & 3,17 & 22,30 & 4,01 &,- 16 \\
\hline Ausência de Confronto & 37,05 & 6,32 & 37,92 & 6,61 & 0,51 \\
\hline Clima Emocional & 49,00 & 8,42 & 54,50 & 8,69 & 2,41 \\
\hline \multicolumn{6}{|l|}{ Competências Sociais } \\
\hline Autocontrole & 0,95 & 0,30 & 1,17 & 0,53 & $2,15^{*}$ \\
\hline Cooperação & 1,25 & 0,34 & 3,97 & 0,45 & $24,68 * * *$ \\
\hline Asserção & 1,15 & 0,27 & 1,20 & 0,51 & 0,58 \\
\hline P. Externalizados & 1,07 & 0,54 & 0,23 & 0,37 & $-6,55^{* * *}$ \\
\hline P. Internalizados &, 75 & 0,38 & 0,96 & 0,12 & $-7,92 * * *$ \\
\hline Hiperatividade & 1,04 & 0,34 & 0,34 & 0,42 & $-6,75 * * *$ \\
\hline
\end{tabular}

Nota: $* \mathrm{p}<0,05 ; * * * \mathrm{p}<0,001$

maltratadas são vistas pelos seus cuidadores como menos competentes socialmente e como apresentando mais problemas externalizados e menos problemas internalizados de comportamento do que as crianças não maltratadas (ver Tabela 1). As diferenças são estatisticamente significativas $(0,036<p<0,0001)$.

\section{A experiência de Maus-Tratos e as Representações acerca das Figuras Parentais nas Competências Sociais}

A fim de perceber a associação entre as representações das crianças e a sua competência social, efetuou-se uma análise 
Tabela 2. Correlações entre as representações das crianças e as escalas de habilidades sociais

\begin{tabular}{|c|c|c|c|c|c|c|c|c|c|c|c|c|}
\hline \multirow[t]{2}{*}{ Dimensões / Categorias } & \multicolumn{3}{|c|}{ Autocontrole } & \multicolumn{3}{|c|}{ Cooperação } & \multicolumn{3}{|c|}{ Asserção } & \multicolumn{3}{|c|}{ Habilidades sociais } \\
\hline & Total & NM & M & Total & NM & M & Total & NM & M & Total & NM & M \\
\hline Grupo & $-0,23+$ & & & $-0,95 * * *$ & & & $-0,06$ & & & $-0,17$ & & \\
\hline NSE & $0,28^{*}$ & & & $0,33 * *$ & & & 0,21 & & & $0,24+$ & & \\
\hline Aceitação & $0,29 *$ & $0,29+$ & 0,22 & $0,22+$ & 0,25 & 0,03 & $0,22+$ & 0,29 & $-0,06$ & $0,27 *$ & 0,30 & 0,08 \\
\hline Rejeição & $-0,27 *$ & $-0,29+$ & $-0,35$ & $-0,00$ & $-0,25$ & $-0,05$ & $-0,20$ & $-0,29$ & 0,03 & $-0,24+$ & $-0,30$ & $-0,15$ \\
\hline Punição & $-0,34 * *$ & $-0,45^{* *}$ & 0,13 & $-0,24+$ & $-0,42$ & 0,01 & $-0,33^{* *}$ & $-0,47$ & 0,18 & $-0,36 * *$ & $-0,49$ & 0,12 \\
\hline Indução & $0,25+$ & $0,37 *$ & $-0,21$ & 0,08 & 0,34 & 0,36 & $0,40 * *$ & 0,40 & 0,49 & $0,36 * *$ & 0,40 & 0,25 \\
\hline Ausência de Confronto & 0,10 & 0,04 & 0,29 & 0,07 & 0,01 & 0,02 & 0,01 & 0,03 & $-0,10$ & 0,05 & 0,03 & 0,09 \\
\hline Clima Emocional & $0,28 *$ & 0,25 & 0,17 & $0,36^{* *}$ & 0,35 & 0,06 & $0,25 *$ & 0,31 & 0,06 & $0,32 *$ & 0,34 & 0,12 \\
\hline
\end{tabular}

Nota: NM: Não Maltratadas ( $\mathrm{n}=40)$; M: Maltratadas $(\mathrm{n}=22) ;+\mathrm{p}<.10 ; * \mathrm{p}<.05 ; * * \mathrm{p}<.01$

Tabela 3. Correlações entre as representações das crianças e as escalas de problemas de comportamento

\begin{tabular}{|c|c|c|c|c|c|c|c|c|c|c|c|c|}
\hline \multirow[t]{2}{*}{ Dimensões / Categorias } & \multicolumn{3}{|c|}{ P.Externalizados } & \multicolumn{3}{|c|}{ P.Internalizados } & \multicolumn{3}{|c|}{ Hiperatividade } & \multicolumn{3}{|c|}{ P.Comportamento } \\
\hline & Total & NM & M & Total & NM & M & Total & NM & M & Total & NM & M \\
\hline Grupo & $0,68 * * *$ & & & $0,80 * * *$ & & & $0,66^{* * *}$ & & & $0,75 * * *$ & & \\
\hline NSE & $-0,19$ & & & $-0,24+$ & & & $-0,24+$ & & & $-0,21+$ & & \\
\hline Aceitação & $-0,21+$ & $-0,11$ & $-0,17$ & $-0,22+$ & $-0,40$ & $-0,01$ & $-0,21+$ & $-0,16$ & $-0,10$ & $-0,23+$ & $-0,19$ & $-0,12$ \\
\hline Rejeição & 0,09 & 0,11 & 0,24 & $-0,06$ & 0,40 & $-0,28$ & 0,09 & 0,16 & 0,20 & 0,04 & 0,19 & 0,02 \\
\hline Punição & 0,12 & 0,10 & $-0,08$ & $0,23+$ & 0,44 & 0,07 & 0,20 & 0,17 & 0,06 & 0,19 & 0,20 & 0,00 \\
\hline Indução & $-0,02$ & $-0,25$ & 0,25 & $-0,04$ & 0,01 & $-0,21$ & $-0,18$ & $-0,28$ & $-0,20$ & $-0,08$ & $-0,26$ & 0,06 \\
\hline Ausência de Confronto & $-0,11$ & 0,01 & $-0,21$ & $-0,02$ & $-0,26$ & 0,25 & $-0,10$ & $-0,05$ & $-0,12$ & $-0,08$ & $-0,06$ & $-0,01$ \\
\hline Clima Emocional & $-0,29^{*}$ & $-0,21$ & $-0,01$ & $-0,23+$ & $-0,20$ & 0,15 & $-0,37 * *$ & $-0,30$ & $-0,10$ & $-0,30^{*}$ & $-0,28$ & 0,10 \\
\hline
\end{tabular}

Nota: NM: Não Maltratadas ( $\mathrm{n}=40) ;$ M: Maltratadas $(\mathrm{n}=22) ;+\mathrm{p}<.10 ; * \mathrm{p}<.05 ; * * \mathrm{p}<.01$

correlacional. $\mathrm{Na}$ tabela 2, apresentam-se as correlações entre as representações e as habilidades sociais e, na tabela 3 , as correlações entre as representações e os problemas de comportamento.

E possível verificar uma associação muito forte do grupo de pertença com a habilidade de cooperação $(r=-0,95)$ e com os problemas de comportamento $(r=0,75)$, o que leva a pensar que o grupo de pertença será o preditor mais forte dessas variáveis. Por outro lado, o grupo de pertença aparece associado ao autocontrole e à asserção com um valor fraco e nulo, respetivamente. Relativamente ao NSE, considera-se relevante o controle dessa variável, embora as correlações com as competências sociais sejam genericamente baixas, com exceção da cooperação, em que o valor se pode considerar moderado.

A análise das associações observadas nos dois grupos de crianças mostra que os valores das correlações tendem a ser próximos ou têm a mesma direção. Contudo, as correlações entre punição e autocontrole, indução e autocontrole, punição e asserção, indução e problemas externalizados, rejeição e problemas internalizados, e ausência de confronto e problemas internalizados apresentam direções opostas. Estes resultados levam a supor que o grupo de pertença estará a funcionar como variável moderadora dos efeitos dessas representações em algumas das escalas de competência social.
Para estudar os efeitos de interação do grupo de pertença com as representações das crianças, foram construídos modelos de regressão hierárquica com as competências sociais como variáveis dependentes. No primeiro passo de cada modelo, foi incluído o NSE, de modo a controlar o efeito dessa variável. No segundo, foi integrado o grupo de pertença (0: não maltratadas; 1 : maltratadas) e uma das representações acerca das figuras parentais. No terceiro passo, foi introduzida a interação entre o grupo de pertença e as representações. Seguindo as indicações de Aiken e West (1991), as variáveis preditoras foram centradas na média, para evitar problemas de multicolineariedade. Esses modelos são apresentados nas Tabelas 4, 5 e 6 .

A interação de punição e grupo de pertença e a interação de indução e grupo de pertença são ambas significativas na predição do autocontrole (ver Tabela 4). Ao contrário do que acontece nas crianças maltratadas, o acréscimo na punição e a diminuição na indução estão associados a uma diminuição no autocontrole nas crianças não maltratadas.

A interação de punição e grupo de pertença (ver Tabela 5) é significativa na predição da asserção. Nas crianças não maltratadas, verifica-se uma associação negativa entre a punição e a asserção, associação essa que não se verifica nas crianças maltratadas.

A interação da indução e do grupo de pertença (ver Tabela 5) é significativa a um nível de $p=0,07$, na predição dos problemas externalizados, apesar da forte contribuição única do grupo. Nas crianças não maltratadas, observa-se 
Tabela 4. O grupo como moderador da relação entre as representações acerca das figuras parentais e o autocontrole

\begin{tabular}{|c|c|c|c|c|c|c|c|c|c|}
\hline & $B$ & $S E B$ & $\beta$ & $\begin{array}{c}R 2 \text { ajustado } \\
(\Delta R 2)\end{array}$ & & $B$ & $S E B$ & $\beta$ & $\begin{array}{c}R 2 \text { ajustado } \\
(\Delta R 2)\end{array}$ \\
\hline Autocontrole & & & & & Autocontrole & & & & \\
\hline Passo 1 & & & & $0,06 *(0,08)$ & Passo 1 & & & & \\
\hline NSE & 0,27 & 0,12 & $0,28 *$ & & NSE & 0,27 & 0,12 & $0,28 *$ & $0,06 *(0,03 *)$ \\
\hline Passo 2 & & & & $0,13 *(0,10)$ & Passo 2 & & & & \\
\hline NSE & 0,18 & 0,12 & 0,18 & & NSE & 0,19 & 0,12 & 0,20 & $0,11 *(0,08+)$ \\
\hline Grupo & $-0,13$ & 0,12 & $-0,13$ & & Grupo & $-0,17$ & 0,13 & $-0,18$ & \\
\hline Punição & $-0,02$ & 0,01 & $-0,28 *$ & & Indução & 0,03 & 0,02 & 0,23 & \\
\hline Passo 3 & & & & $0,18 * *(0,06 *)$ & Passo 3 & & & & \\
\hline NSE & 0,13 & 0,12 & 0,13 & & NSE & 0,21 & 0,12 & 0,22 & $0,16^{* *}\left(0,06^{*}\right)$ \\
\hline Grupo & $-0,17$ & 0,12 & $-0,17$ & & Grupo & $-0,16$ & 0,12 & $-0,17$ & \\
\hline Punição & $-0,04$ & 0,01 & $-0,47 * *$ & & Indução & 0,05 & 0,02 & $0,37 * *$ & \\
\hline Grupo X Punição & .04 & .02 & $.31 *$ & & Grupo X Indução & -.07 & .04 & $-.29 *$ & \\
\hline
\end{tabular}

Tabela 5. O grupo como moderador da relação entre as representações acerca das figuras parentais e os problemas externalizados

\begin{tabular}{|c|c|c|c|c|c|c|c|c|c|}
\hline & $B$ & $S E B$ & $\boldsymbol{\beta}$ & $\begin{array}{c}R 2 \text { ajustado } \\
(\Delta R 2)\end{array}$ & & $\boldsymbol{B}$ & $S E B$ & $\beta$ & $R 2$ ajustado $(\triangle R 2)$ \\
\hline Asserção & & & & & Problemas Externalizados & & & & \\
\hline Passo 1 & & & & $0,03(0,04)$ & Passo 1 & & & & $0,02(0,04)$ \\
\hline NSE & 0,19 & 0,11 & 0,21 & & NSE & $-0,23$ & 0,15 & $-0,19$ & \\
\hline Passo 2 & & & & $0,09 *(0,09+)$ & Passo 2 & & & & $0,44 * * *(0,44 * * *)$ \\
\hline NSE & 0,15 & 0,12 & 0,16 & & NSE & 0,04 & 0,12 & 0,04 & \\
\hline Grupo & 0,03 & 0,12 & 0,04 & & Grupo & 0,86 & 0,12 & $0,70 * * *$ & \\
\hline Punição & $-0,02$ & 0,01 & $-0,31 *$ & & Indução & -01 & 0,02 & $-0,04$ & \\
\hline Passo 3 & & & & $0,16 * *\left(0,08^{*}\right)$ & Passo 3 & & & & $0,47 * * *(0,03+)$ \\
\hline NSE & 0,09 & 0,11 & 0,10 & & NSE & 0,03 & 0,12 & 0,02 & \\
\hline Grupo & $-0,01$ & 0,12 & $-0,01$ & & Grupo & 0,85 & 0,12 & $0,69^{* * *}$ & \\
\hline Punição & $-0,04$ & 0,01 & $-0,52 * *$ & & Indução & $-0,02$ & 0,02 & $-0,14$ & \\
\hline Grupo X Punição & 0,04 & 0,02 & $0,36^{*}$ & & Grupo X Indução & 0,07 & 0,04 & $0,20+$ & \\
\hline
\end{tabular}

Nota: $* \mathrm{p}<0,05 ; * * \mathrm{p}<0,01$

Tabela 6. O grupo como moderador da relação entre as representações acerca das figuras parentais e os problemas internalizados

\begin{tabular}{|c|c|c|c|c|c|c|c|c|c|}
\hline & B & SE B & $\beta$ & $\begin{array}{c}\mathrm{R} 2 \text { ajustado } \\
(\Delta \mathrm{R} 2)\end{array}$ & & B & SE B & $\beta$ & $\begin{array}{c}\mathrm{R} 2 \text { ajustado } \\
(\Delta \mathrm{R} 2)\end{array}$ \\
\hline $\begin{array}{l}\text { Problemas } \\
\text { Internalizados }\end{array}$ & & & & & $\begin{array}{l}\text { Problemas } \\
\text { Internalizados }\end{array}$ & & & & \\
\hline Passo 1 & & & & & Passo 1 & $-0,20$ & 0,10 & $-0,24+$ & $0,04+(0,06+)$ \\
\hline NSE & $-0,20$ & 0,10 & $-0,24+$ & $0,04+(0,06+)$ & NSE & & & & \\
\hline Passo 2 & & & & $\begin{array}{c}0,61 * * * \\
\left(0,57^{* * *}\right)\end{array}$ & Passo 2 & $\begin{array}{c}0,61 * * * \\
(0,58 * * *)\end{array}$ & & & \\
\hline NSE & 0,00 & 0,07 & 0,01 & & NSE & 0,01 & 0,07 & 0,01 & \\
\hline Grupo & 0,66 & 0,07 & $0,80 * * *$ & & Grupo & 0,66 & 0,07 & $0,80 * * *$ & \\
\hline Rejeição & $-0,00$ & 0,01 & $-0,02$ & & Indução & 0,00 & 0,01 & 0,03 & \\
\hline Passo 3 & & & & $\begin{array}{l}0,64 * * * \\
(0,04 *)\end{array}$ & Passo 3 & & & & $\begin{array}{l}0,63 * * * \\
(0,02+)\end{array}$ \\
\hline NSE & 0,04 & 0,07 & 0,05 & & NSE & 0,02 & 0,07 & 0,03 & \\
\hline Grupo & 0,66 & 0,07 & $0,80 * * *$ & & Grupo & 0,67 & 0,07 & $0,81 * * *$ & \\
\hline Punição & 0,01 & 0,01 & 0,13 & & Indução & $-0,01$ & 0,01 & $-0,08$ & \\
\hline Grupo X Punição & $-0,03$ & 0,01 & $-0,24 *$ & & Grupo X Indução & 0,02 & 0,01 & $0,19+$ & \\
\hline
\end{tabular}

Nota: $* \mathrm{p}<0,05 ; * * \mathrm{p}<0,01$ 
uma associação negativa entre a indução e os problemas de comportamento, que não se verifica nas crianças maltratadas.

As interações da rejeição e do grupo de pertença, bem como da ausência de confronto e do grupo de pertença, são significativas na predição dos comportamentos internalizados (ver Tabela 6). Enquanto, nas crianças não maltratadas, o aumento da rejeição e a diminuição da ausência de confronto correspondem a um aumento dos problemas internalizados, nas crianças maltratadas, essas associações não são observadas.

\section{Discussão}

A análise comparativa das representações acerca das figuras parentais nos dois grupos aponta para a ausência de diferenças na forma como as crianças maltratadas e não maltratadas representam as figuras parentais. Segundo a hipótese representacional, esperar-se-ia que as crianças que sofreram experiências de maus-tratos representassem as figuras parentais como mais rejeitantes e punitivas do que as não maltratadas. Contudo, os resultados deste estudo não oferecem suporte a essa predição, uma vez que apontam para a possibilidade de as narrativas das crianças maltratadas consistirem em uma reconstrução subjetivamente filtrada das experiências familiares, permeada por mecanismos de regulação emocional. Esses mecanismos visam proteger a criança do confronto com as emoções negativas associadas à experiência de maus-tratos (Clyman, 2003). Nesse sentido, as narrativas dessas crianças podem refletir uma idealização das interações com as figuras parentais, ou distanciar-se significativamente das suas vivências pessoais. Trata-se, assim, de um processo eminentemente emocional, frequentemente observado em crianças vítimas de maustratos, que se veem forçadas a gerir a emocionalidade associada à experiência de maus-tratos.

Relativamente às diferenças encontradas nas competências sociais nos dois grupos, os resultados são consistentes com as conclusões da investigação nesse domínio, dado que as crianças maltratadas são percebidas como menos competentes socialmente (Milot et al., 2010) e como apresentando mais problemas internalizados (Bolger \& Patterson, 2001) e externalizados (Johnson et al., 2002, Toth et al., 2000).

Os resultados mostram que as representações se encontram associadas a algumas das habilidades sociais e problemas de comportamento, tendo essas associações direções contrárias, nas crianças maltratadas e não maltratadas. Corroboram a influência decisiva das representações mentais nas competências sociais, reforçando a pertinência de aprofundar a análise dos processos psicológicos que explicam as associações observadas. A análise das representações das crianças acerca das figuras parentais permite cumprir esse objetivo.

De uma forma global, é possível afirmar que, nas crianças não maltratadas, as representações dos comportamentos parentais indutivos estão associadas a maior habilidade social e a menos problemas de comportamento. Por sua vez, as representações negativas das figuras parentais como punitivas e rejeitantes estão associadas a menos habilidades sociais e a mais problemas de comportamento.
Esse padrão de associações não se verifica nas crianças maltratadas. Nessas crianças, a representação positiva das figuras parentais prediz menos habilidades sociais e mais problemas de comportamento externalizados, enquanto a representação dessas figuras como punitivas não tem um efeito significativo nas habilidades sociais. Por sua vez, a representação das figuras parentais como rejeitantes prediz menos problemas de comportamento internalizados. A representação de ausência de confronto, habitualmente associada a um estilo educativo permissivo, prediz positivamente os problemas internalizados nas crianças maltratadas, não apresentando um efeito significativo nas não maltratadas. Esses resultados, aparentemente incoerentes, necessitam de ser lidos do ponto de vista da criança e dos significados por ela imputados às suas experiências familiares.

Nas crianças não maltratadas, o comportamento disciplinar indutivo é, porventura, entendido como potencializando um espaço de diálogo, em que os pais respeitam os filhos como pessoas com interesses e necessidades próprias. Acresce que as representações das figuras disciplinares como recorrendo a esse tipo de estratégia disciplinar estão associadas a níveis superiores de competência social (Hart, DeWolf, Wozniak, \& Burts, 1992). As representações das crianças maltratadas sobre os comportamentos parentais indutivos são diferentes das construídas pelas crianças não maltratadas. O espaço de diálogo e negociação, em que o adulto explica à criança as regras e os limites, modelando alternativas comportamentais mais ajustadas, configura-se, nas narrativas das crianças maltratadas, como promotor de desregulação comportamental. Afiguram-se plausíveis duas justificativas para esses resultados. A primeira baseia-se na hipótese da regulação emocional, segundo a qual essas crianças parecem construir representações sobre as figuras parentais de uma forma aparentemente dissonante face à sua experiência, tentando compensar, na narrativa, aquilo que percebem como desejável na abordagem educativa das figuras parentais. A segunda reporta-se ao contexto educativo em que ocorrem as interações com as figuras parentais. Quando um comportamento disciplinar positivo surge em um contexto relacional marcado pelos maus-tratos físicos e psicológicos, pode ser confundido pela criança com a inexistência de normas de conduta, ou sentido como fonte de insegurança e imprevisibilidade.

Nas crianças não maltratadas, o comportamento punitivo está associado a menor competência social, sendo esse resultado consistentemente apoiado pela literatura (cf. Laible et al., 2004). Porém, nas crianças maltratadas, esse efeito não se verifica e tende até a inverter-se. A hipótese da regulação emocional pode ajudar a compreender esses resultados, no sentido em que preconiza que as crianças maltratadas tendem a apresentar representações que não são reproduções fidedignas das suas vivências familiares. Uma outra possibilidade é que a punição seja entendida por essas crianças como normativa (todos os pais o fazem), ou mesmo como um comportamento que traduz um momento de atenção exclusiva à criança, passível de ser confundido com a manifestação de afeto (Baumrind, 2012).

Nas crianças não maltratadas, o comportamento de rejeição está associado a mais problemas internalizados. 
Contudo, essa relação inverte-se nas crianças maltratadas. Mais uma vez, a hipótese da regulação emocional permite explicar esses resultados aparentemente paradoxais, reforçando a assunção de que as narrativas infantis são uma reconstrução formatada por um crivo emocional. Poderá também acontecer que as crianças maltratadas que representam as figuras parentais como mais rejeitantes tendam a apresentar mais problemas de externalização do que internalização. Além disso, as manifestações dos problemas internalizados são, porventura, diferentes nas crianças maltratadas e não maltratadas. Acresce que as crianças maltratadas podem desenvolver mecanismos de resiliência que lhes permitam lidar com a vulnerabilidade física e emocional associada à experiência de maus-tratos.

Finalmente, no que se refere à representação da ausência de confronto, não é evidente o significado que, quer as crianças maltratadas quer as não maltratadas, atribuem a esse comportamento. A ausência de confronto aparece associada a mais problemas de internalização nas crianças maltratadas. É, pois, possível que essas crianças signifiquem esse tipo de comportamento como correspondendo a ausência ou negligência parental, traduzindo uma permissividade excessiva ou uma ausência de limites.

Em síntese, os resultados permitem concluir que: (a) as crianças maltratadas e não maltratadas tendem a representar de forma semelhante as figuras parentais, sendo as suas narrativas influenciadas quer pelas suas representações quer por mecanismos de regulação emocional; (b) as crianças maltratadas são percebidas como sendo menos competentes socialmente e como apresentando mais problemas de comportamento; (c) a experiência de maus-tratos modera os efeitos das representações das crianças acerca das figuras parentais nas habilidades sociais e nos problemas de comportamento, o que leva a supor que os comportamentos parentais assumem diferentes significados para os dois grupos de crianças. É, todavia, necessária mais evidência empírica para apoiar essas conclusões.

Esta investigação apresenta algumas limitações, entre as quais se destaca o reduzido número de participantes, sobretudo no grupo de crianças maltratadas. Essa limitação inviabilizou a inclusão simultânea do conjunto das representações como preditoras, em um único modelo de regressão. Impossibilitou também a integração simultânea do tipo de mau trato e do tempo de institucionalização nos modelos construídos. Neste sentido, este estudo tem um cariz exploratório, devendo os resultados ser analisados de forma cautelosa.

Embora não tenha sido observada uma associação da idade nem com as representações acerca das figuras parentais nem com as competências sociais, uma segunda limitação deste estudo relaciona-se com a maior amplitude etária no grupo das crianças maltratadas. Em estudos futuros, será importante homogeneizar a distribuição das idades das crianças.

O fato de a avaliação da competência social se basear só na perceção dos professores constitui uma terceira limitação. Seria, por isso, importante alargar o leque de informantes, de modo a possibilitar uma avaliação compreensiva do funcionamento da criança.
Apesar dessas limitações, este estudo contribuiu para preencher uma lacuna na investigação. As representações que as crianças maltratadas constroem sobre as figuras parentais têm um efeito na sua competência social diferente do que se observa nas crianças com um percurso desenvolvimental normativo. É, desta forma, crucial que a investigação permita aprofundar a compreensão da forma como as crianças (re) constroem e significam narrativamente as suas experiências afetivas significativas.

Por último, estes resultados reforçam a necessidade de analisar as consequências da experiência de vitimação no ajustamento social da criança. Assim, será possível desenhar intervenções que se ofereçam como experiências desconfirmatórias, potencializando a reconstrução das representações sobre as figuras parentais e a gestão das emoções a ela associadas.

\section{Referências}

Aiken, L., \& West, S. (1991). Multiple Regression: Testing and interpreting interactions. Newbury Park: Sage.

Amato, P., \& Fowler, F. (2002). Parenting practices, child adjustment, and family diversity. Journal of Marriage and Family, 64, 703-716. doi: 10.1111/j.1741-3737.2002.00703.x

Barnett, D. (1997). The effects of early intervention on maltreating parents and their children. In M. J. Guralnick (Ed.), The effectiveness of early intervention (pp. 147-170). Baltimore: Paul Brookes.

Baumrind, D. (2012). Differentiating between confrontative and coercive kinds of parental power-assertive disciplinary practices. Human Development, 55, 35-51. doi: 10.1159/000337962

Bolger, K., \& Patterson, C. (2001). Pathways from child maltreatment to internalizing problems: Perceptions of control as mediators and moderators. Development and Psychopathology, 13, 913-940. doi: 10.1186/s12888-015-0512-z

Bretherton, I., \& Oppenheim, D. (2003). The MacArthur Story Stem Battery: Development, administration, reliability, validity, and reflections about meaning. In R. Emde, D. Wolf, \& D. Oppenheim (Eds.), Revealing the inner worlds of young children: The MacArthur Story Stem Battery and parent-child narratives (pp.81-91). Oxford: University Press.

Buchsbaum, H., Toth, S., Clyman, R., Cicchetti, D., \& Emde, R. (1992). The use of a narrative story stem technique with maltreated children: Implications for theory and practice. Development and Psychopathology, 4, 603-625

Clyman, R. (2003). Portrayals in maltreated children's play narratives: Representations or emotion regulation? In R. Emde, D. Wolf, \& D. Oppenheim (Eds.), Revealing the inner worlds of young children: The MacArthur Story Stem Battery and parentchild narratives (pp. 201-221). Oxford: University Press.

Cruz, O. (1999). O autocontrolo em crianças de cinco anos: Implicações educativas das vivências familiares. Psicologia: Teoria, Investigação e Prática, 4, 109-130.

Culp, R., Howell, C., Culp, A., \& Blankemeyer, M. (2001). Maltreated children's emotional and behavioral problems: Do teachers and parents see the same things? Journal of Child and Family Studies, 10, 39-50. doi: 10.1023/A:1016631111859 
Custódio, S., \& Cruz, O. (2008). As representações mentais das crianças acerca das figuras parentais. Psicologia: Teoria e Pesquisa, 24, 393-405. doi: 10.1590/S010237722008000400002

Gershoff, E. (2002). Corporal punishment by parents and associated child behaviors and experiences: A meta-analytic and theoretical review. Psychological Bulletin, 18, 539-579. doi: 10.1037//0033-2909.128.4.539

Gresham, F., \& Elliott, S. (1990). Social skills rating system: Manual. Circle Pines, MN: American Guidance Service.

Hart, C., DeWolf, D., Wozniak, P., \& Burts, D. (1992). Maternal and paternal disciplinary styles: Relations with preschooler's playground behavioral orientations and peer status. Child Development, 63, 879-892.

Herzberger, S., Potts, D., \& Dillon, M. (1981). Abusive and nonabusive parental treatment from the child's perspective. Journal of Consulting and Clinical Psychology, 49, 81-90.

Johnson, R., Kotch, J., Catellier, D., Winsor, J., Dufort, V., Hunter, W., \& Amaya-Jackson, L. (2002). Adverse behavioral and emotional outcomes from child abuse and witnessed violence. Child Maltreatment, 7, 179-186. doi: 10.1177/1077559502007003001

Klimes-Dougan, B. \& Kistner, J. (1990). Physically abused preschoolers' responses to peers' distress. Developmental Psychology, 26, 599-602.

Koenig, A., Cichetti, D., \& Rogosch, F. (2004). Moral development: The association between maltreatment and young children's prosocial behaviors and moral transgressions. Social Development, 13, 87-106. doi: 10.1111/j.14679507.2004.00258.x.

Laible, D., Carlo, G., Torquati, J., \& Ontai, L. (2004). Children's perceptions of family relationships as assessed in a doll story completion task: Links to parenting, social competence, and externalizing behavior. Social Development, 13, 551-569. doi: 10.1111/j.1467-9507.2004.00283.x

Lemos, M., \& Meneses, H. (2002). A avaliação da competência social: Versão portuguesa da forma para professores do SSRS. Psicologia: Teoria e Pesquisa, 18, 267-274. doi: 10.1590/ S0102-37722002000300005

Macfie, J., Toth, S., Rogosch, F., Robinson, J., Emde, R., \& Cicchetti, D. (1999). Effect of maltreatment on preschoolers' narrative representations of responses to relieve distress and of role reversal. Developmental Psychology, 35, 460-465.

Maughan, A., \& Cicchetti, D. (2002). The impact of child maltreatment and interadult violence on children's emotion regulation abilities. Child Development, 73, 1525-1542. doi: 10.1111/1467-8624.00488

Milot, T., Éthier, L., St-Laurent, D., \& Provost, M. (2010). The role of trauma symptoms in the development of behavioral problems in maltreated preschoolers. Child Abuse \& Neglect, 34, 225-234. doi: 10.1016/j.chiabu.2009.07.006
Muris, P., Meesters, C., \& van der Berg, S. (2003). Internalizing and externalizing problems as correlates of self-reported attachment style and perceived parental rearing in normal adolescents. Journal of Child and Family Studies, 12, 171-183. doi: 10.1023/A:1022858715598

Oppenheim, D., Emde, R. \& Warren, S. (1997). Children's narrative representations of mothers: Their development and associations with child and mother adaptation. Child Development, 68, 127-138.

Shields, A., Ryan, R., \& Cicchetti, D. (2001). Narrative representations of caregivers and emotion dysregulation as predictors of maltreated children's rejection by peers. Developmental Psychology, 37, 321-337. doi: 10.1037// OO12-1649.37.3.321

Solomonica-Levi, D., Yirmiya, N., Erel, O., Samet, I., \& Oppenheim, D. (2001). The associations among observed maternal behaviour, children's narrative representations of mothers, and children's behaviour problems. Journal of Social and Personal Relationships, 18, 673-690. doi: 10.1177/0265407501185006

Straker, G., \& Jacobson, R. (1981). Aggression, emotional maladjustment, and empathy in the abused child. Developmental Psychology, 17, 762-765.

Torres, N., Maia, J., Veríssimo, M., Fernandes, M., \& Silva, F. (2012). Attachment security representations in institutionalized children and children living with their families: Links to problem behaviour. Clinical Psychology and Psychotherapy, 19, 25-36. doi: 10.1002/cpp.739

Toth, S., Manly, J., \& Cicchetti, D. (1992). Child maltreatment and vulnerability to depression. Development and Psychopathology, 4, 97-112.

Toth, S., Cicchetti, D., Macfie, J., \& Emde, R. (1997). Representations of self and other in the narratives of neglected, physically abused, and sexually abused preschoolers. Development and Psychopathology, 9, 781-796.

Toth, S., Cicchetti, D., Macfie, J., Rogosch, F., \& Maughan, A. (2000). Narrative representations of moral-affiliative and conflictual themes and behavioral problems in maltreated preschoolers. Journal of Clinical Child Psychology, 29, 307318. doi: 10.1207/S15374424JCCP2903 2

Waldinger, R., Toth, S., \& Gerber, A. (2001). Maltreatment and internal representations of relationships: Core relationship themes in the narratives of abused and neglected children. Social Development, 10, 41-58. doi: 10.1111/1467-9507.00147

Warren, S. (2003). Narratives in risk and clinical populations. In R. Emde, D. Wolf, \& D. Oppenheim (Eds.), Revealing the inner worlds of young children: The MacArthur Story Stem Battery and parent-child narratives (pp.92-105). Oxford: University Press. 